\title{
Experiències d'aula amb el treball amb Controvèrsies Sòcio-Científiques. Educació per al Desenvolupament i la Salut, Pseudociències i eines per a l'avaluació d'activitats
}

\author{
Jordi Domènech-Casal (jdomen44@xtec.cat) Institut de Granollers i Departament de Didàctica de la \\ Matemàtica i les Ciències Experimentals, Universitat Autònoma de Barcelona. \\ Iván Marchán-Carvajal (imarcha2@xtec.cat) Professor de ciències a l'Institut Europa (L'Hospitalet de \\ Llobregat) i professor associat a la Facultat d'Educació de la UB. \\ Quique Vergara (evergara@maristes.com) Escola Maristes Champagnat, Badalona.
}

Les controvèrsies sòcio-científiques (o CSC) i la Recerca i Innovació Responsables són contexts candidats per a ubicar l'ensenyament de les ciències en conflictes rellevants. Es presenten diverses activitats d'aula al voltant de les pseudociències, l'educació pel desenvolupament i l'educació per a la salut, i es proposen eines i bastides didàctiques per acompanyar el treball a l'aula amb CSC.

Paraules clau: Controvèrsies, RRI, Pseudociències, Educació pel Desenvolupament, Assaig.

Socio-Scientific Issues (SSI) and Responsible Research and Innovation are candidate contexts for Science Education in relevant conflicts. We present several classroom activities on pseudo-sciences and education for Development and Health and we propose tools and didactic scaffolds to guide students' work in the classroom when using CSC.

Keywords: Socio-Scientific Issues, RRI, Pseudo-Sciences, Education for Development, Essay.

\section{INTRODUCCIÓ}

Els nous marcs metodològics (ECBI, Ciència en context, STEM) i programes de millora institucionals (Competències Bàsiques, PISA), posen l'èmfasi en que els alumnes desenvolupin habilitats científiques per a identificar i construir models científics i transferir-los a nous contexts (Hodson, 1994), desenvolupin una visió crítica del món que els envolta (Solbes, 2013) i prenguin decisions ben fonamentades en contextos de la vida real participats per models científics (Sanmartí, Burgoa, y Nuño, 2011, OCDE, 2013). Des d'aquesta visió pren sentit l'educació basada en contextos, una metodologia que fa servir situacions reals i rellevants per a estructurar l'aprenentatge de les idees clau i promoure que l'alumnat en pugui fer un ús competent (Blanco et al., 2012). Tot entenent el terme "context"des de l'educació científica com aquella situació que es fa servir per a explorar les idees prèvies de l'alumnat sobre un temàtica $\mathrm{i}$ reformular-les per tal que s'aproximin a les teories de la ciència de manera que aquestes teories siguin necessàries per a resoldre una problemàtica o interpretar científicament un fenomen que apareix al context (Marchán-Carvajal i Sanmartí, 2015).

\section{Les controvèrsies Sòcio-Científiques, un context candidat}

Aquest enfoc, a cavall entre l'Alfabetització Científica i la Ciutadania Crítica, troba en les Controvèrsies Sòcio-Científiques (CSC) un paisatge candidat. Les CSC són qüestions o 
dilemes socialment rellevants amb vincles conceptuals amb la Ciència i que tenen respostes obertes i complexes, en les que participen també els valors personals i aspectes ètics i legals (Jiménez-Aleixandre, 2010). Les controvèrsies sociocientífiques són un exemple de contextos per a estructurar l'aprenentatge perquè són actuals, reals i rellevants personalment, socialment i vocacionalment (Domènech et al., 2015). A més, representen una oportunitat per al treball interdisciplinari perquè permeten múltiples mirades des de les diferents disciplines científiques (física, biologia, química i geologia) però també des de disciplines socials i humanístiques (psicologia, economia, història...).

Un dels contexts rellevants en l'educació científica de la ciutadania és la presa de decisions fonamentades en els àmbits personals (consumir drogues o no?) o socials (estil de vida consumista o sostenible?) (Sanmartí i Marchán-Carvajal, 2015). El context de la salut en particular troba en les pseudociències un espai per a la controvèrsia: criticades per alguns però defensades per uns altres i amb un notable ús per part de la població.

\section{Una Ciència per a tots, la Recerca i Innovació Responsables}

La Unió Europea, dintre de l'Horitzó 2020, promou que la ciència i la tecnologia sigui no només excel•lent sinó que també desitjable a nivell social, dirigint els objectius dels processos d'investigació i innovació amb les necessitats i valors de les societats que els recolzen, involucrant a la societat en les decisions en matèria de ciència i tecnologia. La iniciativa RRI (Responsible Research and Innovation) vol contribuir al creixement intel-ligent, sostenible $i$ inclusiu de les nostres societats i posa l'accent el la pràctica de la ciència i la innovació amb la societat i per a la societat, incloent la societat en les etapes inicials dels processos d'investigació i innovació per alinear els seus resultats amb els valors de la societat.

Una de les actuacions què com a educadors pren major sentit és la Educació pel desenvolupament (EPD). UNICEF 2001, defineix la Educació pel desenvolupament com un procés que "fomenta el desenvolupament, en joves $i$ infants, d'actituds $i$ valors com ara la solidaritat d'àmbit mundial, la pau, la tolerància, la justícia social i la consciència respecte a qüestions ambientals i que dota de coneixements $i$ aptituds que els permeten promoure aquests valors $i$ fer canvis, tant personals com en la comunitat on viu, a escala local i global'

\section{Les dificultats del treball amb CSC}

Tot i aquestes oportunitats metodològiques, les controvèrsies sòcio-científiques (CSC) s'usen poc a les aules de secundària, principalment per dificultats del professorat en les estratègies d'aula i l'avaluació d'aquestes activitats (Evagorou, Guven, i Mugaloglu, 2014) i la formulació de dilemes que estimulin el debat (McNeill i Knight, 2013). També l'alumnat troba difícil abordar el treball amb CSC, en particular a l'hora d'avaluar els diferents tipus d'informacions d'un context (Sadler i Zeidler, 2009) - les dificultats per a elaborar argumentacions escrites o orals (Solbes, Ruiz i Furió, 2010).

En aquest article proposem diverses activitats didàctiques al voltant de les pseudociències, la salut i l'Educació per al Desenvolupament, i eines per facilitar el treball amb Controvèrsies SòcioCientífiques, aplicades a les aules dels Instituts de secundària Europa (L'Hospitalet de Llobregat), Maristes Champagnat i INS Vilanova del Vallès durant els cursos 2013-2014 i 2014-2015.

\section{RECURSOS I PROPOSTES}

\section{1) Seqüències didàctiques d’Educació pel Desenvolupament. Coltan, Texans i Vacunes}

La visió i les accions de la solidaritat entre països han evolucionat les últimes dècades des d'una visió assistencialista des del Nord als anys 50 cap a unes postures més situades en la cooperació on la incidència al Nord porta a denunciar, i actuar al mateix Nord contra les estructures injustes que incideixen sobre el desenvolupament al Sud (Polo 2004).

L'Educació pel Desenvolupament proposa incloure en el disseny de les seves propostes didàctiques des del treball cooperatiu, a partir de situacions de conflicte, treballant els problemes de manera global amb una intervenció mínima del docent i enfocant les situacions amb optimisme i l'acció des del compromís personal. Com a exemples de propostes de treball amb Controvèrsies Sòcio-Científiques en el marc específic de l'Educació pel Desenvolupament, s'han dut a terme un conjunt d'activitats que es descriuen a continuació. 


\begin{tabular}{|c|c|c|}
\hline CSC treballada & Proposta EPD & Enllaços de referència \\
\hline $\begin{array}{l}\text { Think Twice } \\
\text { (1r Batx) }\end{array}$ & $\begin{array}{l}\text { El punt de partida de l'activitat és la comparació a tots nivells de les tecnologies de } \\
\text { telefonia mòbil de dues marques utilitzades majoritàriament. Els alumnes avaluen la } \\
\text { tecnologia, comparen pel que fa a la percepció de les marques i prenen decisions amb la } \\
\text { informació disponible. } \\
\text { S'introdueix el concepte d'externalitats i a partir d'una reflexió conjunta surt la necessitat } \\
\text { de saber més sobre les condicions de treball i l'impacte ambiental de la producció } \\
\text { d'aquestes tecnologies. } \\
\text { L'alumnat proposa teballar la situació d'explotació de recursos naturals no renovables i } \\
\text { en particular la situació del Coltan a zones de centre d'Àfrica. La resposta davant del } \\
\text { coneixement de l'alumnat és crear una acció de ciberactivisme amb les xarxes socials } \\
\text { per denunciar l'ús irracional del mòbil. }\end{array}$ & $\begin{array}{l}\text { Web de la Campanya Think } \\
\text { Twice } \\
\text { http://bit.ly/1NB0APA }\end{array}$ \\
\hline $\begin{array}{l}\text { Això té tela } \\
(3 r \text { ESO) }\end{array}$ & $\begin{array}{l}\text { A partir d'un treball sobre el sistema respiratori es planteja la problemàtica del } \\
\text { sandblasting (tractament industrial dels texans) i la silicosi que provoca als treballadors. } \\
\text { El projecte ha evolucionat cap a una proposta interdiciplinar al coneixement de } \\
\text { l'explotació laboral, al voltant del negoci de la roba duta a terme en el marc del treball de } \\
\text { síntesi amb una setmana de duració i organitzada amb un format de webquest. } \\
\text { La proposta parteix del treball cooperatiu, aprofundint en temes socials, laborals, } \\
\text { ambientals i s'enfoca sobretot a l'anàlisi dels patrons de consum personals i a les } \\
\text { possibles accions que es poden dur a terme de manera individual. }\end{array}$ & $\begin{array}{l}\text { WEBQUEST Això té tela. } \\
\text { http://everga89.wix.com } \\
\text { /wqaixotetela } \\
\text { Desfilada solidària } \\
\text { https://youtu.be/WNKbs } \\
\text { ARrnSY. }\end{array}$ \\
\hline $\begin{array}{l}\text { Les vacunes com a } \\
\text { dret } \\
(1 \mathrm{rBatx})\end{array}$ & $\begin{array}{l}\text { Treballant materials de salut de projecte Xplorehealth (Alcaraz-Domínguez et al, 2015), } \\
\text { es proposa als alumnes l'elaboració d'un vídeo animat sobre les desigualtats en l'accés } \\
\text { al tractament mèdic amb especial atenció a la situació de la malària. }\end{array}$ & $\begin{array}{l}\text { Exemples de vídeos dels } \\
\text { alumnes } \\
\text { http://bit.ly/1PpqWDD } \\
\text { http://bit.ly/1 VNtxHi }\end{array}$ \\
\hline
\end{tabular}

Figura 1. Taula resum activitats proposades EPD i CSC.

\section{2) Seqüències didàctiques en el context de la Salut, la Ciència i la Pseudociència. Homeopatia, Desintoxicació lònica i Tabaquisme}

Es proposen dues unitats didàctiques al voltant de dos contexts amb presència habitual en el dia a dia que connecten pseudociències i el món de la salut.

\section{Proposta 1: Homeopatia}

En aquesta activitat es demanava als alumnes redactar un text argumentatiu amb les seves parts essencials (idea defensada, raons, contraarguments, evidències...) sobre la següent qüestió: "Creus que s'han de vendre medicament homeopàtics a les farmàcies?"

La unitat comença explorant el coneixement previ de l'alumnat a través d'una discussió col•lectiva en que alguns alumnes expliquen el que han escoltat de l'homeopatia. Molts en prenen sense saber-ho i ho fan per a tractar l'asma o al-lèrgies. La pregunta clau que emergeix de la discussió és: "L'homeopatia funciona?". En cas afirmatiu, com ho fa? En cas negatiu, per què tanta gent la pren i es ven a les farmàcies?

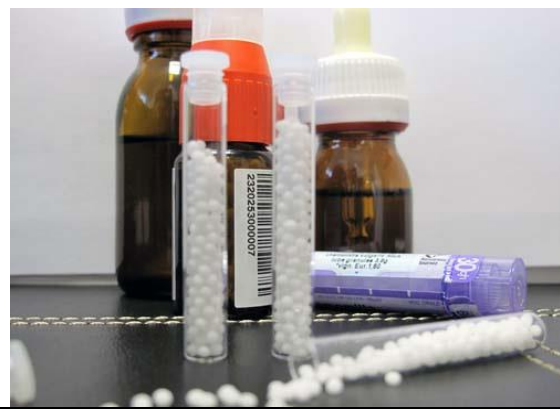

Figura 2. Imatge d'uns medicaments homeopàtics en forma de boles de sacarosa

Un cop consensuat l'objectiu d'aprenentatge es fa palesa la necessitat de tenir més informació sobre aquest tractament farmacèutic i per fer-ho vam veure a l'aula el reportatge del programa "Quequicom": "Homeopatia, creença o evidència?"[1]. L'alumnat apunta dubtes i aspectes 
controvertits del que es va dient al vídeo i al final fem una posta en comú amb les seves inquietuds.

Des de la química, el vídeo permet introduir de manera contextualitzada un concepte difícil de relacionar amb la vida quotidiana: el mol. Es fa servir el concepte de mol per a justificar que després de moltes dilucions la probabilitat de que quedi alguna molècula en solució és molt baixa. Altres idees clau de la química que es fan servir per a comprendre el vídeo són la preparació de dissolucions, els factors de dilució i la concentració. Pel que fa a les idees sobre la naturalesa de la ciència, el vídeo permet treballar amb l'alumnat la diferència entre creença i evidència però també ofereix una imatge de la ciència com una disciplina oberta i canviant que té encara molts fronts oberts com per exemple la comprensió de l'efecte placebo.

\section{Proposta 2: Desintoxicació iònica:}

La segona SEA comença preguntant a la l'alumnat si sap en que consisteixen els tractaments de desintoxicació iònica. Cap dels alumnes amb els que s'ha aplicat la SEA n'havia sentit parlar. Malgrat això, se'ls proposa que infereixin en que deu consistir un suposat tractament mèdic amb aquest nom per tal d'explorar les seves idees prèvies sobre què són les toxines i els ions. A continuació se'ls presenta un anunci publicitari del Youtube sobre un aparell de desintoxicació iònica[2] i se'ls demana que vagin apuntant dubtes o aspectes controvertits del que defensa l'anunci. Després d'una posta en comú tot l'alumnat està d'acord amb que aquest tractament té pinta de ser un frau, però es tracta només d'una intuïció atès que no disposem d'evidències.

La tasca que proposem a l'alumnat és dissenyar un experiment que demostri que la desintoxicació iònica és una estafa per tal de fer-lo públic a la web del centre i conscienciar a la gent del barri sobre aquest tipus de pràctiques fraudulentes. Per tant, des de la naturalesa de la ciència vam treballar les etapes d'una investigació científica: problema, hipòtesi, disseny experimental, resultats i conclusió. Atès que el vídeo mostra l'aparició d'una nova substància, la mirada al problema des de la química va permetre aprofundir en la interpretació del canvi químic que tenia lloc a tres nivells: el nivell perceptible (s'observa un canvi de color i un bombolleig), el nivell simbòlic (fórmules i equacions químiques) i el nivell sub-microscòpic (partícules que es reorganitzen i enllaços que es trenquen i es formen).

Una possible activitat de continuació que l'alumnat demana és l'estudi dels aparells d'osmosi inversa que els comercials venen per les cases.
Una de les proves que fan per a "evidenciar" la gran quantitat de brutícia que hi ha a l'aigua de l'aixeta consisteix en fer un reacció electrolítica semblant a la que té lloc en la desintoxicació iònica.

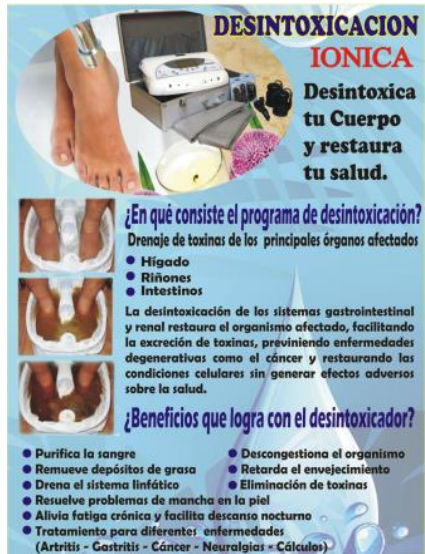

Figura 3. Anunci sobre la desintoxicació iònica i els seus beneficis.

\section{Proposta 3: El tabaquisme:}

A partir de la proposta Fumes?[3], de Ramon Grau s'han treballat aspectes de tabac, càncer i addicció i s'ha encarregat als alumnes el desenvolupament d'una campanya de sensibilització. Els alumnes treballen amb dades epidemiològiques $\mathrm{i}$ mèdiques, $\mathrm{i}$ duen a terme debats i activitats de lectura crítica que els ajuden a identificar els arguments clau en els dilemes i controvèrsies associats al tabaquisme, i a adoptar un rol crític i actiu davant de la problemàtica. Com a proposta d'aplicació els alumnes es proposen treballar amb un fumador proper (familiar, amic, professor) durant un mes de manera planificada $\mathrm{i}$ guiada per tal de deixar l'addicció.

\section{3) Eines per al treball amb Controvèrsies}

En el treball amb els dilemes proposats i amb altres controvèrsies, l'elecció del dilema i l'organització del debat hi juguen un paper essencial, així com el producte en el que es demana a l'alumne un posicionament argumentat, que acostuma a ser un assaig breu, que sovint no sabem com avaluar. Com que aquestes solen ser qüestions en les que hi ha dificultats, hem partit de la proposta Word Generation , una seqüència estandarditzada originalment dedicada a l'aprenentatge de lèxic específic (Snow et al, 2009, Lawrence et al, 2010) i testada amb èxit en escoles de Boston, EEUU. Partint d'aquesta proposta, hem construït bastides de suport que ajudin a que el professorat pugui desenvolupar i aplicar activitats 
CSC en 4 passos breus i que desemboquin en la creació d'un producte individual avaluable. Aquesta proposta i les bastides de suport estan disponibles a la página CSCFrame[4], i s'estructura en 4 passes:

1) Proposta d'un dilema sòcio-científic.

2) Lectura col-laborativa de textos relacionats, consensuant els termes de lèxic claus.

3) Debat en gran grup sobre el dilema.

4) Escriptura i co-avaluació d'un assaig individual de 400 paraules (mig full).

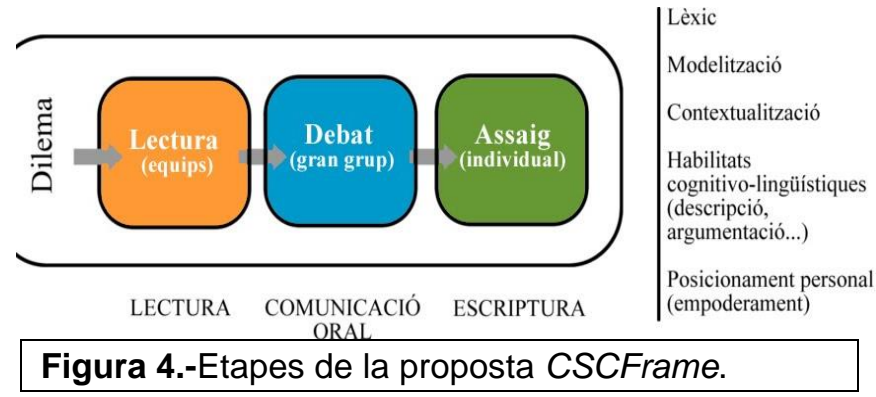

\section{LECTURA I DEBAT}

Per a aquestes dues etapes s'han preparat fitxes d'ajut per a l'alumnat, orientades a:

1) La lectura crítica: els alumnes llegeixen els diversos textos $\mathrm{i}$ en discerneixen diversos aspectes (Idees, Rol, Dades, Models, Lèxic) amb l'ajut de la fitxa TextTest, desenvolupada partint d'experiències prèvies d'altres autors (Prat, Márquez i Marbà, 2008).

2) El debat productiu: Es proposa a l'alumnat una fitxa en la que ha de completar quina és la seva opinió davant el dilema (abans del debat), els arguments a favor i en contra que recull (durant el debat) i la seva opinió, de nou, al final del debat.

\section{ESCRIPTURA. EINES PER A L'ESCRIPTURA I AVALUACIÓ D'UN ASSAIG}

Es proporcionen diverses bastides de suport:

1) Dos exemples d'assajos similars al que ha d'escriure, però sobre altres temes.

2) Una plantilla per a elaborar el seu assaig i un llistat de passos que cal seguir.

3) La rúbrica McLeares elaborada ad hoc per al marc metodològic que es proposa.

La rúbrica McLeares obté el seu nom dels ítems que avalua (Model, Context, Lèxic, Argumentació i Estructura formal), que comprenen tant aspectes lingüístics com l'ús correcte dels Models científics implicats en el dilema, la seva correcta Contextualització i ús de dades reals, i l'ús pertinent del lèxic específic. Són disponibles 3 activitats contextualitzades elaborades seguint aquesta proposta d'estructura sobre diverses temàtiques (transgènics, biodiversitat $\mathrm{i}$ determinisme genètic)[5].

\begin{tabular}{|c|c|c|c|}
\hline & 2 & 1 & 0 \\
\hline Lèxic & $\begin{array}{l}\text { S'usen 4-5 termes del lèxic específic de forma } \\
\text { pertinent i parafrasejant-lo o relacionant-lo amb } \\
\text { altres termes. }\end{array}$ & $\begin{array}{l}\text { S'usen } 2 \text { o } 3 \text { termes del lèxic específic de forma } \\
\text { pertinent. No se n'inclouen més, o no queda clar } \\
\text { la seva relació entre si i amb el dilema. }\end{array}$ & $\begin{array}{l}\text { S'usen menys de } 2 \text { termes específics de forma } \\
\text { pertinent. S'inclouen termes com a llistes de } \\
\text { definicions. }\end{array}$ \\
\hline Model & $\begin{array}{l}\text { El model científic que s'usa s'expressa } \\
\text { explícitament i es relaciona amb el dilema. }\end{array}$ & $\begin{array}{l}\text { Es cita el model científic (de manera directa o } \\
\text { indirecta) però no s'usa suficientment en } \\
\text { l'argumentació. }\end{array}$ & $\begin{array}{l}\text { No es cita el model científic implicat en el } \\
\text { dilema de cap manera. }\end{array}$ \\
\hline Context & $\begin{array}{l}\text { S'aporten dades (numèriques, estadístiques,...) } \\
\text { i com a mínim dos exemples de situacions } \\
\text { concretes i reals que il.lustrin el dilema o la } \\
\text { seva importància. }\end{array}$ & $\begin{array}{l}\text { S'aporta algun exemple del món real per a } \\
\text { clarificar alguna idea o illlustrar el dilema o la } \\
\text { seva importància. }\end{array}$ & $\begin{array}{l}\text { No s'aporten exemples ni dades externes al } \\
\text { dilema. L'argumentació es basa en opinions } \\
\text { d'experts o de tercers. }\end{array}$ \\
\hline Argumentació & $\begin{array}{l}\text { S'usen connectors gramaticals adequats i els } \\
\text { arguments són coherents entre si. S'anticipen } \\
\text { els contra-arguments i es neutralitzen. S'usen } \\
\text { èmfasis i puntuació com a reforç. }\end{array}$ & $\begin{array}{l}\text { S'usa algun connector, però preval la descripció. } \\
\text { Alguns dels arguments és poc coherent amb la } \\
\text { resta, o desatén els contra-arguments. No s'usa } \\
\text { èmfasis. }\end{array}$ & $\begin{array}{l}\text { Es tracta bàsicament d'una descripció i no } \\
\text { sembla intentar convèncer ningú. No usa } \\
\text { connectors adequats. }\end{array}$ \\
\hline $\begin{array}{l}\text { Estructura } \\
\text { formal i cohesió }\end{array}$ & $\begin{array}{l}\text { L'estructura formal és correcta (Títol, Sub-Títol, } \\
\text { Dades, Argumentació, Contra-Argumentació) i } \\
\text { cada secció compleix la seva funció en el } \\
\text { discurs. No hi ha contradiccions internes. }\end{array}$ & $\begin{array}{l}\text { L'estructura general és correcta, però alguna } \\
\text { secció conté tipus fragments descol·locats, o no } \\
\text { compleix completament amb la seva funció en el } \\
\text { discurs. }\end{array}$ & $\begin{array}{l}\text { El text és desordenat i sense fil conductor. No } \\
\text { sembla que avanci en el desenvolupament } \\
\text { d'una idea i es fa difícil identificar les parts de } \\
\text { l'assaig. Hi ha contradiccions internes. }\end{array}$ \\
\hline
\end{tabular}

Figura 5. Versió resumida de la Bastida Mc Leares d'avaluació d'assajos científics, que permet obtenir una nota sobre 10 a partir de diversos ítems que relacionen ciència i llengua 


\section{CONCLUSIONS I PERSPECTIVES}

Considerem que les activitats i eines proposades han estat d'utilitat per ajudar els nostres alumnes a connectar els aspectes científics amb contexts rellevants. Durant la implementació hem identificat una millora notable de la motivació a l'aula i l'interès per la disciplina (major nombre de vocacions científiques) però també un aprenentatge més significatiu de les idees clau de la ciència que promou que es puguin utilitzar de manera competent per a actuar en un món canviant i complex.

Les experiències d'aules estan d'acord amb els resultats de recerques educatives internacionals que mostren millores educatives (afectives i cognitives) quan es fan servir contextos rellevants per a l'alumnat (Ültay i Çalık, 2011). Tanmateix, portar a l'aula aquesta manera de fer requereix un canvi metodològic del professorat (i pot requerir formació permanent) ja que identificar contextos rellevants i connectar-los amb tots els continguts curriculars que marca la legislació és una tasca complexa.

En particular, l'adopció d'aquest tipus d'activitats implica prioritzar l'activitat cooperativa, plantejar situacions conflictives $i$ donar importància a la negociació com a possible solució.

Cal que els esdeveniments socials i científics es presentin de manera global amb connexions als interessos dels alumnes, mantenint les tasques el més obertes i diverses possible, i perseguint sempre l'orientació del coneixement a l'acció, i l'adquisició de compromisos personals o grupals a favor de valors ètics com de la justícia social, l'argumentació científica i la conservació del medi ambient.

En aquest sentit, hi ha diferents experiències a nivell europeu on es proposen la inclusió d'aspectes de ciutadania global en l'educació en tecnologia; com la iniciativa GDEE (Global Dimension in Engineering Education http://gdee.eu/index.php/about-gdee) i el projecte Practical action http://practicalaction.org/home on es promou la relació de la tecnologia amb el fet d'aconseguir els objectius de desenvolupament humà. Pensem que incloure els conceptes bàsics de la educació pel desenvolupament dintre de l'anàlisi de les controvèrsies socio-científiques és una passa endavant en la construcció d'una ciutadania global. Els contextos, en ocasions llunyans, poden esdevenir més propers incloent la visió de la solidaritat, la empatia i la emoció fent possible un aprenentatge més significatiu.

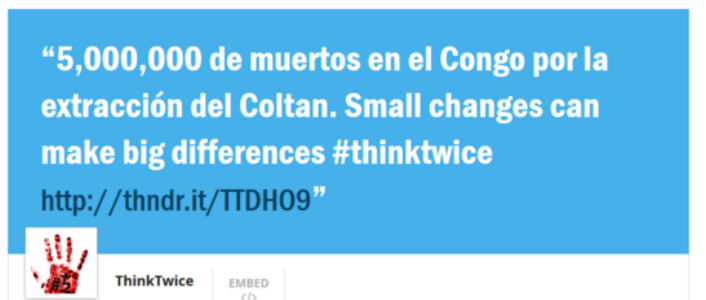

REGISTRADOS 120 of $\mathbf{5 0 0}$ ALCANCE SOCIAL $\mathbf{5 2 , 1 0 6}$ TIEMPO RESTANTE Completo

Figura 6. Campanya sobre el Coltan elaborada per els alumnes, amb més de 50000 impactes.

Des d'un punt de vista lingüístic, la participació en Controvèrsies Sòcio-Científiques implica demandes cognitives (justificació, argumentació, descripció,...) (Jorba, Gómez i Prat, 1998, Solbes, 2010) i lingüístiques (debats, assajos, lectura crítica) que poden ser ateses amb l'ajut de bastides lingüístiques que ajudin a professorat i alumnat a fer que les CSC siguin un habitant habitual i sostenible a les aules. En concret, pensem que la proposta CSCFrame, a més de treballar el lèxic, permet el desenvolupament de les quatre competències comunicatives (gramatical, discursiva, sociolingüística y estratègica) (Canale, 1983), a més d'ajudar l'alumnat a posicionar-se personalment davant dilemes participats per models científics.

Des de perspectives complementàries sobre les CSC, el lector pot trobar d'interès també materials d' altres articles publicats en aquest mateix número de la revista ciències (Alcaraz-Domínguez et al, 2015, Farró et al, 2015) com a part de les Jornades sobre Controvèrsies Sòcio-Científiques i Recerca i Innovació Responsables \#cscrri15 (DomènechCasal i Lope, 2015).

\section{AGRAIIMENTS}

Aquest article recull el contingut de tres ponències presentades pels autors a les "Jornades de Controvèrsia Sòcio-Científica i Recerca i Innovació Responsables. Ciències per a qüestionar i canviar el món. Pensar, comprendre, decidir." [https://cienciaicontroversia.wordpress.com/] que es van celebrar els dies 21-X, 4-XI i 25 XI de 2015 al CESIRE de Barcelona (Drassanes) del Departament d'Ensenyament de la Generalitat de Catalunya. Part de les eines i experiències recollides en aquest article s'emmarquen en la reflexió metodològica del grup LIEC (Llenguatge i Ensenyament de les Ciències) de la Universitat Autònoma de Barcelona -grup de recerca consolidat (referència 2014SGR1492) per AGAUR (Agència de Gestió d'Ajuts Universitaris i de 
Recerca) finançat per el Ministerio de Educación y Ciencia (referència EDU-2012-38022-C02-02)- i l'activitat formativa del Servei d'Acollida i Immersió Lingüística de la Generalitat de Catalunya.

Els autors agraeixen la participació i suport als alumnes i professors de l'Institut Vilanova del Vallès, Col•legi Maristes Champagnat i Institut Europa de l'Hospitalet de Llobregat i la tasca de la ONGD, Solidaritat Educació i Desenvolupament, SED.

\section{Bibliografia}

ALCARAZ-DOMÍNGUEZ, S., BARAJAS, M., MALAGRIDA, R., PÉREZ, F. (2015). Els projectes Europeus Engaging Science, Xplore Health, RRI Tools i Scientix. Finestres a la formació i la participació en comunitats docents per al treball amb Controvèrsies $i$ Recerca $i$ Innovació Responsables. Revista Ciències (aquest mateix número).

BLANCO, Á., ESPAÑA, E., RODRÍGUEZ, F. (2012). Contexto y enseñanza de la competencia científica. Alambique: Didáctica de las ciencias experimentales, 70, 9-18.

CANALE, M. (1983). De la competencia comunicativa a la pedagogía comunicativa del lenguaje, pp 63-81 dins M. Llobera (ed) (1995), La competencia comunicativa. Barcelona, Edelsa.

DOMĖNECH, A., MÁRQUEZ, C., MARBÀ, A., ROCA, M. (2015). La medicalización de la sociedad, un contexto para promover el desarrollo y uso de conocimientos científicos sobre el cuerpo humano. Enseñanza de las ciencias: revista de investigación y experiencias didácticas, 33(1), 101-125.

DOMÈNECH-CASAL, J. (2014), Contextos de indagación y controversias socio-científicas para la enseñanza del Cambio Climático. Enseñanza de las Ciencias de la Tierra, 22(3), 267-276.

DOMĖNECH-CASAL, J. (en avaluació). Propuesta de un marco para la secuenciación didáctica de Controversias Socio-Científicas. Estudio con dos actividades alrededor de la genética. Revista Eureka de Enseñanza y Divulgación de las Ciencias, en avaluació.

DOMÈNECH-CASAL, J., LOPE, S. (2015). Les Jornades de Controvèrsia Sòcio-Científica $i$ Recerca i Innovació Responsables. Ciències per a qüestionar $i$ canviar el món. Pensar, comprendre, decidir. Revista Ciències (aquest mateix número).
FARRÓ, L., LOPE, S., MARBÀ, A., OLIVERAS, B. (2015). Les Controvèrsies Sòcio-Científiques com a contextos d'aprenentatge i comunicació a l'aula. Anàlisi crítica de la informació $i$ habilitats comunicatives. Revista Ciències (aquest mateix número).

JORBA, J., GÓMEZ, I., PRAT, A. (1998). Parlar i escriure per aprendre. Barcelona: Institut de Ciències de l'Educació.

MARCHÁN-CARVAJAL, I., SANMARTÍ, N. (2015). Criterios para el diseño de unidades didácticas contextualizadas: aplicación al aprendizaje de un modelo teórico para la estructura atómica. Educación Química, 26(4), 267-274. http://doi.org/10.1016/j.eq.2015.06.001

LAWRENCE, J., WHITE, C., SNOW, C. (2010). The words students need. Educational Leadership, 68 (2), 22-26.

POLO, F. (2004). Cap a un currículum per una ciutadania global. Intermón Oxfam.

PRAT, A., MÁRQUEZ, C., MARBÀ, A. (2008). Literacitat científica i lectura. Temps d'Educació, 34.

SANMARTÍ, N. (coord.) (2003). Aprendre ciències tot aprenent a escriure Ciència. Barcelona: Ed 62.

SANMARTÍ, N., MARCHÁN-CARVAJAL, I. (2015). La educación científica del siglo XXI: retos y propuestas. Investigación y ciencia, Octubre.

ÜLTAY, N., ÇALIK, M. (2011). A Thematic Review of Studies into the Effectiveness of ContextBased Chemistry Curricula. Journal of Science Education and Technology, 21(6), 686-701. http://doi.org/10.1007/s10956-011-9357-5

UNICEF (2003). Educació pel desenvolupament, un recurs per l'aprenentatge global.

[1] Vídeo disponible a:

https://www.youtube.com/watch?v=WNfYerKybJU

[2] Vídeo disponible a:

https://www.youtube.com/watch?v=BJqCwbea_Tw

[3] Activitat disponible a:

http://ateneu.xtec.cat/wikiform/wikiexport/_media/for mgest/dir_novells/din1/bloc_7/exemple_ccee_2.pdf

[4] Web CSC Frame disponibles a: https://sites.google.com/site/cscframe/

[5] Activitats CSCFrame disponibles a:

Biodiversitat (1 ESO): http://apliense.xtec.cat/arc/node/30274;

Determinisme genètic (4 ESO): http://apliense.xtec.cat/arc/node/30273;

Transgènics (4 ESO): http://apliense.xtec.cat/arc/node/30354. 